\title{
The Use of interactive multimedia in balancing redox reactions for facilitating learning style differences
}

\author{
Sukarmin*, Suyono \\ Department of Chemistry \\ Faculty of Mathematics and Natural Sciences \\ Universitas Negeri Surabaya \\ Surabaya, Indonesia \\ sukarmin@unesa.ac.id
}

\begin{abstract}
This study aims to determine, students' learning styles, the improvement of learning outcomes, and student responses to interactive multimedia. The Interactive multimedia "ChemTutor" in balancing redox reactions to be applied in research class. The results of this research showed that from 15 students in the research class is divided into $46.7 \%$ accomodation, $20 \%$ diverger, $20 \%$ converger, and $13,3 \%$ assimilator. ChemTutor is suitable to be applied to all the student's learning style with high learning outcomes improvement. Students with diverger, assimilator, diverger, and converger learning styles gave a positive response.
\end{abstract}

Keywords-Learning Style, Interactive Multimedia, Balancing redox reactions

\section{INTRODUCTION}

The Student develops in different conditions and environments. This will cause different motivation levels and different ways of learning. A person's tendency or orientation in the learning process is influenced by four learning models namely feeling, thinking, watching, and doing [1]. The four models are then divided into four types of Learning Style Inventory (LSI): diverger, assimilator, diverger, and converger [1]. Teachers should map the learning styles of students to find out their learning styles, so that the learning process can accommodate all learning styles of students and the concepts delivered can be received correctly [2].

The materials in chemistry lesson are divided into three levels of thinking there are macro, sub-micro and symbolic. Macro-level refers to the phenomenological: what can be perceived by the senses without instruments help. Sub-micro level refers to something that can only be perceived with the help of instruments or abstracted by the conclusions of chemical processes. Symbolic levels refer to the symbols, models, and equations. To understand the chemical material, three levels must be properly manipulated [3]. The main barrier to understanding chemical material is not all levels are presented [4]. Difficulties that often experienced by students are at abstract levels, which are the sub-microscopic and symbolic. Another thing to note is that students have difficulty if all three levels are presented at the same time. It is associated with each student's memory capacity [3].

With the advancement of technology, demands for presenting chemical material macroscopically, submicroscopically, and symbolic can be done by using learning multimedia. Multimedia is packaged an interactive format, for setting to match the memory capacity of students. In learning on the topic of electrolysis $96.7 \%$ of students expressed interest in the use of interactive multimedia [5]. Students agreed that visualization and animation help them to understand the chemistry concept, but there is a small part of students who stated that using the model (visualization and animation) can be distracting and if overused can be tedious [6]. Students have difficulty in interpreting more complex animations and information described by the computer animation can be a source of misconceptions [7].

Equalizing Redox Reactions material is a material that involving more symbolic thinking and macroscopic levels, namely the fact of the reaction and writes down a complete reaction. There are seven stages to equalize redox reactions [8]. A procedural material in which there are stages that must be impassable, the suitable learning is establishing direct instruction with stages as sets, explanation and/or demonstration, guided practice, feedback, and extended practice [9].

Based on the above description, learning on the equivalency of redox reaction material by using interactive multimedia will be done. Multimedia is presenting the facts of the reaction, reaction stages, exercising, and evaluation. The question posed in this study were 1) How the composition of the student's learning style? 2) How is the student learning outcomes? 3) How the students' response to multimedia?.

\section{RESEARCH METHOD}

\section{A. Samples and learning styles}

This research was conducted in X grade of high school, with 15 students. To figure out the learning styles, use the Kolb Learning Styles Inventory by entering a chemical. This instrument consists of 12 questions and 4 possible answers. In answering, students were asked to rank as desired. With the help of the Microsoft Excel Program, we can be determined the value for Concrete Experiences (CE), Reflective Observation (RO), Abstract Conceptualization (AC), and Active Experimentation (AE). The Data of each student then plotted on $\mathrm{X}-\mathrm{Y}$ axis, where the axis $\mathrm{X}=\mathrm{AE}$ $\mathrm{RO}$ and axis $\mathrm{Y}=\mathrm{AC}-\mathrm{CE}$. From the results plotting obtained student's learning style, which includes diverger, assimilator, diverger, and converger. 


\section{B. Multimedia}

The multimedia used in this research is "Chemtutor" multimedia [11]. The components of the multimedia comprising:

\section{1) Opening}

The opening is a view that first appears when the program starts.

\section{2) Menu Options}

There are six menu options provided in this learning media.

a) Media Directive Usage consisted of a single page view that contains explanations used buttons and their respective functions

b) Basic Competence, indicator and learning objectives which consists of basic competencies clarification, indicators and learning objectives to be achieved.

c) Apersepsi, where on this menu there is the concept of oxidation-reduction reaction that begins with experimental video $\mathrm{Zn}$ metal dipped into the $\mathrm{CuSO}_{4}$ liquid mixture and its animation sub macroscopic.

d) The material, it consists of equalizing reaction material comprising the equalization of redox reaction with the oxidation number method and the redox reaction equalization with half-reaction method.

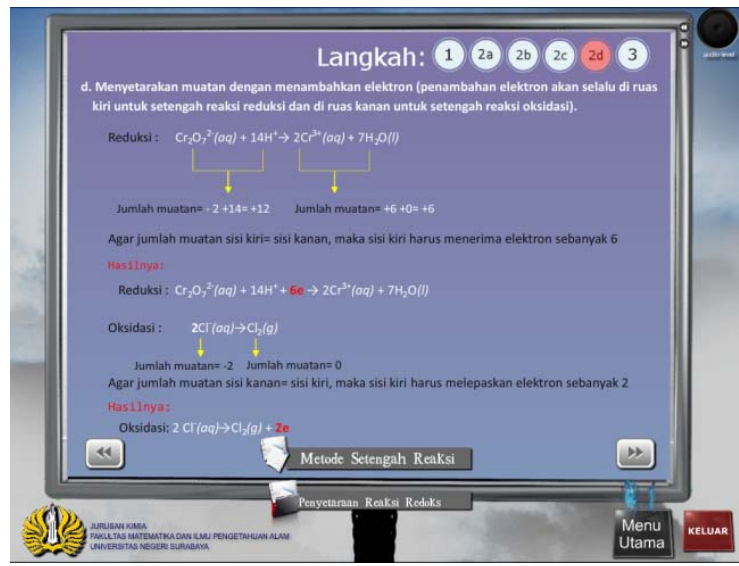

Figure 1. Example of multimedia display

\section{3) Exercise and evaluation questions}

Exercises are intended to train students to work on the problems relating to the determination of the oxidation number and oxidation-reduction reaction equalization. The answer to exercises on redox reaction equalization is done every step. After all, exercises finished, students can check the answer.

\section{Instruments of learning outcomes}

The test exercises consisted of pretest and posttest. Pretest and posttest problems contain of questions to resolve redox reactions equalization using half-reaction method. Given a redox reaction is not equal yet, and the student is asked to equalize it using 6 stages in accordance presented in multimedia. Stages 1 to 6 is conditional stages, meaning that if there is any mistake in stage 3 , it can be ascertained that stages 4,5 , and 6 are also wrong. In each stage, there is always a pair of reaction, namely the reduction and oxidation. To find the learning outcome improvement, it is calculated by the score-gain formula [10]. The formula is as follows:

$g=\frac{\text { post }- \text { test score }- \text { pretest score }}{\text { maxtmum score }- \text { pretest scere }}$

The score acquisition criteria can be seen in Tabel.1

TABLE 1 SCORE GAIN CRITERIA

\begin{tabular}{|l|l|}
\hline Limitation & Category \\
\hline $\mathrm{g}>0,7$ & High \\
\hline $0,3<\mathrm{g} \leq 0,7$ & Medium \\
\hline $\mathrm{g} \leq 0,3$ & Low \\
\hline
\end{tabular}

III. RESULTS AND DISCUSSION

A. Learning styles

Based on the calculations, obtained learning styles graphic presented in Figure 2.

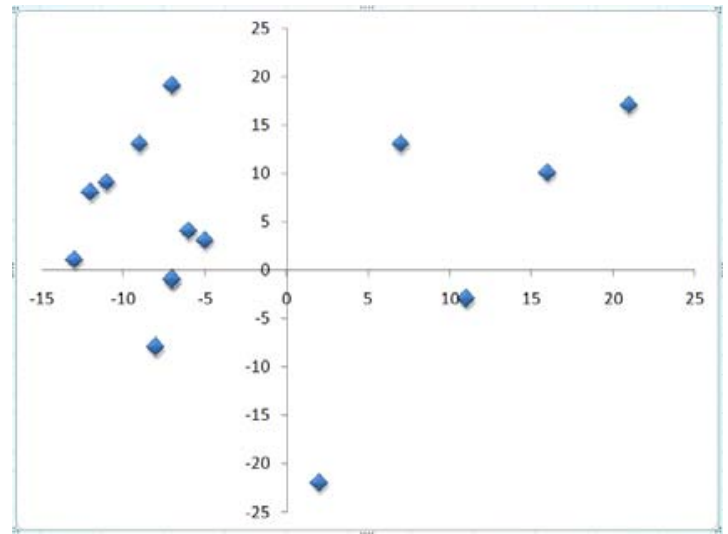

Figure 2 Distributions of Learning Styles

Based on the results of Kolb Learning Styles Inventory data analysis in Figure 2, the distribution of 15 students is as follows: 3 students are Diverger (20\%), 2 students are Assimilator (13.3\%), 3 students are Converger (20\%), and 7 students are accomodator ( $46.7 \%$ ). In Figure 2, there are two marks overlapping in Converger learning styles.

\section{B. Learning outcomes}

Pretest, posttest, and the gain results are presented in table 2

\begin{tabular}{|r|c|c|r|r|r|}
\multicolumn{1}{|c|}{ TABLE 2 RESULTS OF STUDENT LEARNING } \\
\hline No & Name & LS & Pretest & Post-test & \multicolumn{1}{c|}{ gain } \\
\hline 1 & student 01 & Ass & 14 & 93 & 0,9 \\
\hline 2 & student 02 & Div & 64 & 100 & 1 \\
\hline 3 & student 03 & Ass & 14 & 100 & 1 \\
\hline 4 & student 04 & Con & 14 & 72 & 0,7 \\
\hline 5 & student 05 & Acc & 21 & 61 & 0,5 \\
\hline 6 & student 06 & Con & 10 & 100 & 1 \\
\hline 7 & student 07 & Div & 24 & 100 & 1 \\
\hline 8 & student 08 & Acc & 64 & 76 & 0,3 \\
\hline 9 & student 09 & Acc & 24 & 86 & 0,8 \\
\hline 10 & student 10 & Div & 67 & 100 & 1 \\
\hline 11 & student 11 & Con & 50 & 68 & 0,4 \\
\hline
\end{tabular}




\begin{tabular}{|r|c|c|r|r|r|}
\hline No & Name & LS & Pretest & Post-test & \multicolumn{1}{|c|}{ gain } \\
\hline 12 & student 12 & Acc & 10 & 100 & 1 \\
\hline 13 & student 13 & Acc & 66 & 79 & 0,4 \\
\hline 14 & student 14 & Acc & 67 & 79 & 0,4 \\
\hline 15 & student 15 & Acc & 67 & 100 & 1 \\
\hline
\end{tabular}

Statistical test results, presented in Table 3 and Table 4 below

TABLE 3 DESCRIPTION OF STUDENT LEARNING OUTCOMES

\begin{tabular}{|c|r|r|r|r|r|r|}
\hline & $\mathrm{N}$ & Mean & $\begin{array}{c}\text { Std. } \\
\text { Deviation }\end{array}$ & $\begin{array}{c}\text { Std. } \\
\text { Error }\end{array}$ & $\begin{array}{c}\text { Mini } \\
\text { mum }\end{array}$ & $\begin{array}{c}\text { Maxi } \\
\text { mum }\end{array}$ \\
\hline Acc & 7 & 0,6286 & 0,29841 & 0,11279 & 0,30 & 1,00 \\
\hline Ass & 2 & 0,9500 & 0,07071 & 0,05000 & 0,90 & 1,00 \\
\hline Con & 3 & 0,7000 & 0,30000 & 0,17321 & 0,40 & 1,00 \\
\hline Div & 3 & 1,0000 & 0,00000 & 0,00000 & 1,00 & 1,00 \\
\hline Total & 15 & 0,7600 & 0,27980 & 0,07224 & 0,30 & 1,00 \\
\hline
\end{tabular}

TABLE 4 STATISTICAL TESTS OF STUDENT LEARNING OUTCOMES

\begin{tabular}{|c|r|r|r|r|c|}
\hline & $\begin{array}{c}\text { Sum of } \\
\text { Squares }\end{array}$ & df & $\begin{array}{c}\text { Mean } \\
\text { Square }\end{array}$ & F & Sig. \\
\hline Between Groups & 0,377 & 3 & 0,126 & 1,920 & 0,185 \\
\hline Within Groups & 0,719 & 11 & 0,065 & & \\
\hline Total & 1,096 & 14 & & & \\
\hline
\end{tabular}

Based on Table 3 and 4 shows that the gain average for students with accommodations learning style is 0.6286 and converger is 0.7000 . The learning outcomes improvement both groups includes in the middle category. As for the group with assimilator and diverger learning style with gain averages of 0.95 and 1.00 were entered in the high category. However statistically, learning outcome improvement of the four groups, learning styles did not differ significantly with $p$ $=0.185>0.05$.

\section{Student Response}

To find out the students' response to multimedia quality, after learning the students were given a response questionnaire. Student response questionnaire consists of 3 categories, namely content (14 questions), instructional ( 9 questions), and technic (7 questions). The results of student response questionnaires are presented in table 5.

TABLE 5 RESULTS OF STUDENT RESPONSES

\begin{tabular}{|l|c|r|r|r|}
\hline \multicolumn{2}{|c|}{} & \multicolumn{1}{|c|}{$\mathrm{N}$} & \multicolumn{1}{c|}{ Mean } & Std. Deviation \\
\hline \multirow{4}{*}{ Content } & Acc & 7 & 91,8367 & 7,63604 \\
\cline { 2 - 5 } & Ass & 2 & 92,8571 &, 00000 \\
\cline { 2 - 5 } & Con & 3 & 85,7143 & 12,37179 \\
\cline { 2 - 5 } & Div & 3 & 92,8571 & 7,14286 \\
\cline { 2 - 5 } & Total & 15 & 90,9524 & 7,85560 \\
\hline \multirow{7}{*}{ Instructional } & Acc & 7 & 88,8889 & 9,07218 \\
\cline { 2 - 5 } & Ass & 2 & 94,4444 & 7,85674 \\
\cline { 2 - 5 } & Con & 3 & 85,1852 & 12,83001 \\
\cline { 2 - 5 } & Div & 3 & 100,0000 & 0,00000 \\
\cline { 2 - 5 } & Total & 15 & 91,1111 & 9,57657 \\
\hline
\end{tabular}

\begin{tabular}{|l|c|r|r|r|}
\hline \multirow{3}{*}{ Technic } & Acc & 7 & 93,8776 & 16,19848 \\
\cline { 2 - 5 } & Ass & 2 & 100,0000 & 0,00000 \\
\cline { 2 - 5 } & Con & 3 & 90,4762 & 16,49572 \\
\cline { 2 - 5 } & Div & 3 & 100,0000 & 0,00000 \\
\cline { 2 - 5 } & Total & 15 & 95,2381 & 12,85336 \\
\hline
\end{tabular}

Based on table 5 data, the content of the entire group of students gave a positive response. The group of students with learning style accommodation has a mean $=91,8367$ meaning $91,8367 \%$ of questions about multimedia content get a positive response (preferred) by the accommodator students. The average response for content components is $90.9 \%$, instructional components $91.1 \%$, and technic components $95.2 \%$.

\section{Discussion}

Of the 15 students studied, 20\% were Diverger learning styles, $13.3 \%$ Assimilators, 20\% Convergers, and $46.7 \%$ Accommodation. Therefore it is necessary to prepare multimedia that can facilitate the four learning styles.

Examples of multimedia content presented for various types of learning styles are:

1. Accommodation (feeling-doing): Students with an accommodator learning style like direct or concrete activities (hands on experience). Multimedia presents practice questions with tiered difficulty levels accompanied by buttons to check the correctness of the answers.

2. Assimilator (thinking-watching). Students with Assimilator learning styles like theoretical presentation with logical stages. Multimedia presents the stages of equalizing the reaction in order to obtain the results of the number of each left-hand atom at the same time as the right-hand side and the number of left-hand side loads equal to the right segment.

3. Converger (thinking-doing). Students with converger learning styles like the application of a concept or theory. This multimedia in completing the target equalizes the reaction, beginning with the terms of an equivalent reaction then proceeding with a clear step.

4. Diverger (feeling-waching). Students with diverger learning styles like to observe and gather various information. In this multimedia always included a reaction video and sub-microscopic animation for the reaction to be equalized. Then after an equivalent reaction asked what substances change color or settle or become gas in the video that is shown.

The efforts that have been made in order to accommodate various types of learning styles, have received an excellent response. From the aspect of content, instructional, and technic all were responded positively by the four learning style groups. This shows that they feel comfortable using the multimedia.

The learning outcomes achieved showed a high increase with an average gain of 0.76 . Diverger groups have the highest gain, which is 1 thing because the reaction equalization process can be done step by step. The reaction equalization process is presented with easy-to-follow 
animations so the combination of "thinking" understanding the reaction stage and "doing" completing the exercise can be done well. Although the average increase in the results of the four learning style groups is different, the gain of the four groups is not statistically different.

\section{CONCLUSION}

1. The research class consisting of 15 students has a $20 \%$ learning style with Diverger learning style, $13.3 \%$ Assimilator, 20\% Converger, and 46.7\% Accommodation.

2. Improvement of learning outcomes from Diverger, Assimilator, Converger, and Accommodation learning groups is not significantly different and is very good.

3. Multimedia "Chemtutor" received a positive response from the Diverger learning style group, Assimilator, Converger, and Accommodation

\section{ACKNOWLEDGMENT}

The author is very grateful to the Dean as the head of the Faculty of Mathematics and Natural Sciences which has facilitated the completion of this manuscrip. The authors are also grateful to Miko Fitria who has helped set the space and prepare the completeness of the data

\section{REFERENCES}

[1] Kolb, D.A. Experiential learning: experience as the source of learning and development. Englewood Cliffs, NJ: Prentice-Hall, 1984.
[2] Aryungga, Septyadi David Eka., Suyono. Identification of Student Learning Styles Experiencing Misconceptions Resistant to Chemical Concepts (Identifikasi Gaya Belajar Siswa yang Mengalami Miskonsepsi Resisten pada Konsep Kimia). Unesa Journal of Chemical Education, 2014, Vol. 3, No. pp 127-134.

[3] Mbajiorgu. Reid, Factors Influencing Curriculum Development in Chemistry. Physical Sciences Centre Department of Chemistry University of Hull, 2006

[4] Gabel, D. L., Improving Teaching and Learning Through Chemistry Education Research: A Lock to the Future, Journal of Chemical Education, 1999, 76, 548-554.

[5] Febrian P. Sukarmin, Development of Chemo Lysis Multimedia To Reduce Student misconceptions On Electrolysis Matter. Unesa Journal of Chemical Education, May 2014, Vol. 3, No. 2, pp. 255260. Surabaya: Pendidikian Kimia FMIPA UNESA.

[6] Bhawani Venkataraman, Visualization and interactivity in the teaching of chemistry to science and non-science students. Chem. Educ. Res. Pract., 10, 62-69, 2009

[7] Deborah P. Rosenthal and Michael J. Sanger. Student misinterpretations and misconceptions based on their explanations of two computer animations of varying complexity depicting the same oxidation-reduction reaction. Chem. Educ. Res. Pract., 2012, 13, 471-483.

[8] Chang, Raymond. Chemistry Tenth Edition. New York: Mc Graw Hill, 2010

[9] Arends, R.I. Learning to Teach (Fifth ed.). Boston: McGraw-Hill, 2001

[10] Meltzer, David E, The Relationship Between Mathematics Preparation And conceptual learning gain in physics: A possible inhidden Variablei in Diagnostic pretest scores. Ames: Department of physics and Astronomy, Lowa State University, 2002

[11] Aldila Candra Kusumaningrum, Sukarmin. Development of Multimedia Chemtutor in Redox Reaction Material in Class XII High School (Pengembangan Multimedia Chemtutor Pada Materi Reaksi Redoks SMA Kelas XII). Unesa Journal of Chemical Education, 2014, Vol. 3, No. 02, pp. 75-80. 